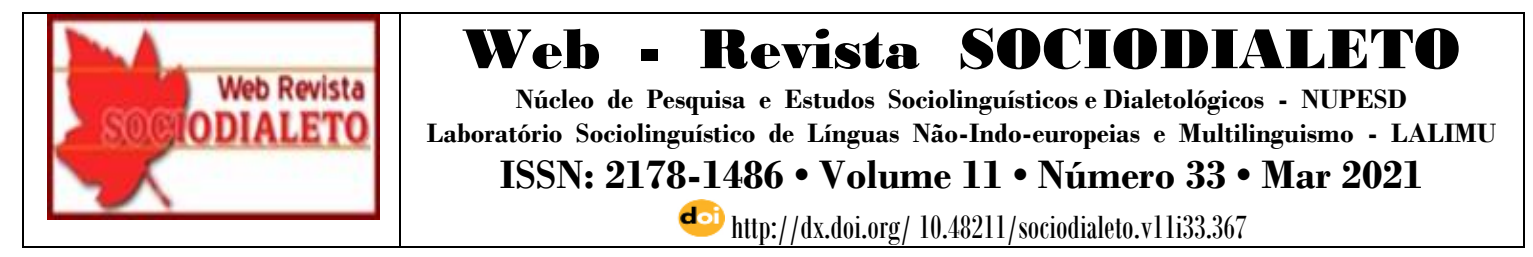

\title{
INTERNETÊS VERSUS ESCRITA FORMAL: A NOVA ESCRITA E SEUS DESDOBRAMENTOS
}

INTERNET STYLE VERSUS FORMAL WRTIING: THE NEW WRTIING AND IIS UNFOLDINGS

\author{
Bárbara Cristina Gallardo (Unemat) ${ }^{1}$ \\ barbarag@unemat.br \\ Eliana Kobayashi (IFSP) ${ }^{2}$ \\ likobayashi@yahoo.com
}

\begin{abstract}
RESUMO: Com o advento da internet, o acesso ao meio digital proporcionou novas formas de comunicação, dentre elas, a escrita com características de fala, em um contexto mais abrangente do que o meio físico, além de um acesso mais abrangente à informação. Com isso, as práticas de leitura e escrita mudaram significativamente, promovendo outros olhares para as inadequações gramaticais e o surgimento de uma escrita própria da internet: o internetês. Neste trabalho, analisamos a reescrita de 4 posts publicados em uma rede social online, realizadas por estudantes do $1^{\circ}$. ano do ensino médio de duas escolas, uma pública e uma privada. O objetivo foi verificar $i$ ) a influência da escrita digital no conhecimento da norma padrão dos participantes; ii) semelhanças e discrepâncias entre os resultados dos dois grupos; iii) o equilíbrio entre os grupos, em relação à consciência dos gêneros textuais e a questões de situacionalidade. A metodologia empregada seguiu os preceitos do estudo de caso, tendo a pesquisa bibliográfica sobre o assunto como embasamento. É um estudo exploratório de natureza quanti-qualitativa, cujo instrumento de coleta foi um handout com a reprodução dos posts retirados de uma rede social e entregues aos estudantes para a leitura, identificação e reescrita de inadequações, próprias da escrita virtual. A fundamentação teórica foi ancorada, principalmente, nas discussões de Freitag e Fonseca e Silva (2006) e Mollica e Batista (2015) sobre as inadequações gramaticais; Komesu e Tanani (2009) sobre o internetês; Marcuschi e Dionísio (2007) sobre a relação entre fala e escrita. Os resultados chamam a atenção para a necessidade da construção de práticas curriculares que contribuam para a conscientização de estudantes sobre o conhecimento de diferentes gêneros textuais, tendo em vista as práticas de leitura e escrita que participam na internet.
\end{abstract}

PALAVRAS-CHAVE: Inadequação gramatical; Internetês; Situacionalidade na escrita; Práticas de leitura e escrita.

\begin{abstract}
With the advent of the internet, access to the digital media has provided new forms of communication, including writing with speech characteristics, in a wider context than the physical one, in addition to a more comprehensive access to information. As a result, reading and writing practices have changed significantly, promoting other perspectives on grammatical inadequacies and the emergence of a writing typical of the internet. In this study, we analyze the rewriting of 4 posts published on an online social network, made by junior high students enrolled in a public and a private school. The objective was to verify: $i$ ) the influence of digital writing on participants' standard norms; $i i$ ) similarities and discrepancies between the results of the two groups; iii) the balance between the two groups concerning the awareness of textual genres and issued of situationality. The methodology used was based on case-study procedures and bibliographic research on studies in this area. It is an exploratory study that used quantitative and qualitative approaches to data. The instrument used to collect data was a handout that reproduced the posts taken form
\end{abstract}

\footnotetext{
${ }^{1}$ Doutora em Linguística Aplicada.

${ }^{2}$ Doutora em Linguística Aplicada.
} 


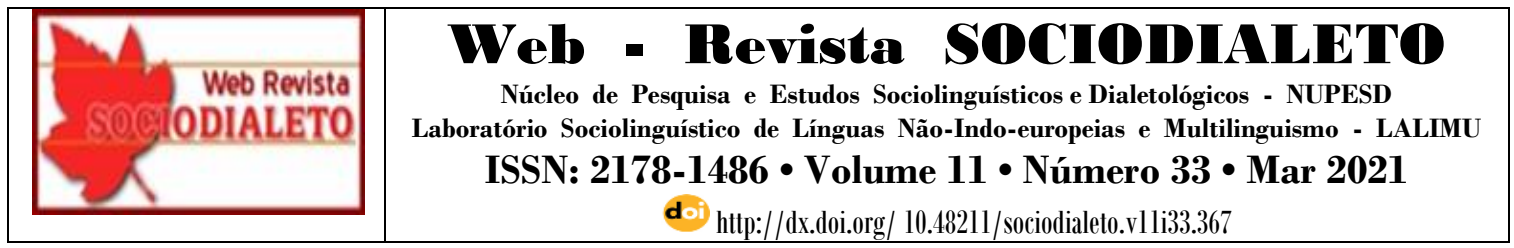

a social network and given to students for reading, identifying and rewriting inadequacies typical of internet writing. The theoretical basis were anchored, mainly, in the discussions of Freitag and Fonseca e Silva (2006); Mollica and Batista (2015) on grammatical inadequacies; Komesu and Tanani (2009) on characteristics of internet writing; Marchuschi and Dionísio (2007) on the relationship between speech and writing. The results highlight the need to build curricular practices that contribute to students' awareness of different textual genres, based on the reading and writing practices that they participate on the internet.

KEYWORDS: Grammatical inadequacy; Internet writing; Situationality in writing practices; Reading and writing practices.

\section{Introdução}

A popularização da Web 2.0 ampliou a participação de usuários da internet nas mídias digitais. A linguagem na forma escrita, meio pelo qual a interação acontece, passou então a ser utilizada de um modo diferente do convencional do meio offline. $\mathrm{O}$ desenvolvimento dessa nova escrita em contextos de interação, em eventos comunicativos do meio online parece, a primeira vista, ter desestabilizado o lugar de destaque da norma padrão da língua portuguesa em detrimento da fala e da variação linguística.

Dentre outros motivos, a escrita no ambiente virtual preocupa os que prezam pela preservação da norma padrão da língua portuguesa, pois trata-se de um novo tipo de escrita, a qual adquire características de fala, incompatíveis com as regras estabelecidas pela norma. Por outro lado, há estudos que advogam que as abreviações, ícones, palavras cifradas e inadequações gramaticais, tal como, o uso indevido de letras para representar o som de uma palavra, representam modos de expressão e interação significativos no contexto onde acontecem, que fogem da dicotomia fala e escrita do aspecto estrutural da língua escrita (KOMESU; TANANI, 2009).

A fim de observar a noção de gênero textual e contexto em duas escolas de nossa cidade, investigamos, neste trabalho, a percepção de estudantes de $1^{\circ}$ ano do ensino médio de inadequações de ordem gramatical e uso do internetês em 4 posts publicados por adolescentes, na rede social Facebook. Inspiradas em pesquisas, tais como a de Freitag e 


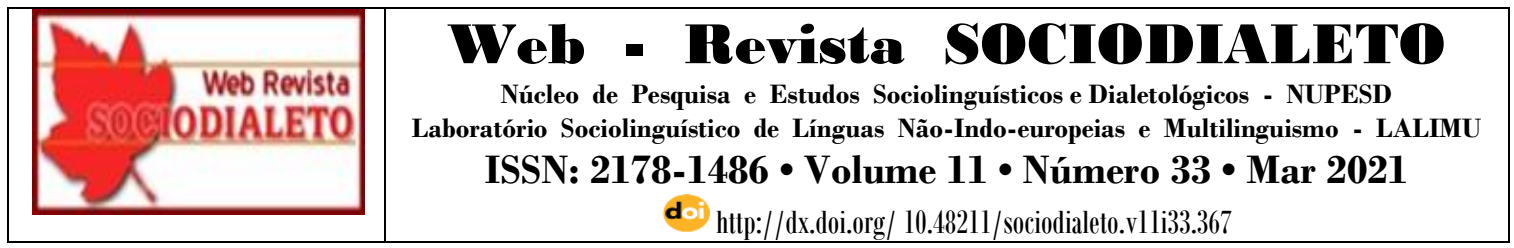

Fonseca e Silva (2006) e Mollica e Batista (2015) propusemos a leitura, identificação e reescrita de inadequações, próprias da escrita virtual. Assim como as pesquisas citadas, seguimos os pressupostos de norma padrão e de variantes da sociolinguística. Propositalmente, essa atividade aconteceu em uma aula de língua portuguesa, no horário regular da escola. Tivemos com isso, a intenção de analisar os efeitos desse contexto ambiente escolar, analógico - na leitura de uma produção não escolar, digital, que não tem o compromisso de seguir as regras aprendidas no ensino formal da escola.

Escolhemos participantes do $1^{\circ}$ ano porque deduzimos que ingressantes do ensino médio são capazes de reconhecer as variantes da língua na escrita formal no contexto escolar e, na língua informal, no contexto das redes sociais digitais. Observamos, então, a análise dos dois grupos, a fim de refletir sobre: $i$ ) a influência da escrita digital no conhecimento da norma padrão dos participantes; ii) semelhanças e discrepâncias entre os resultados dos dois grupos; iii) o equilíbrio entre os grupos, em relação à consciência dos gêneros textuais e a questões de situacionalidade. Nossa hipótese era a de que, se houvesse divergência entre a percepção dos dois grupos, não seria de ordem de categoria - escola pública ou particular - mas de sensibilidade a questões do contexto.

Este estudo tem um caráter de intervenção, uma vez que nosso intuito é o de advogar sobre a inclusão da abordagem dos gêneros digitais populares ${ }^{34}$ no conteúdo do ensino formal, por fazer parte das práticas não escolares que os estudantes participam. Essa prática está embasada na ponderação de Morin (2004) que afirma que "os alunos reclamam do tédio de ficar ouvindo um professor falando na frente por horas, da rigidez dos horários, da distância entre o conteúdo das aulas e a vida”. (p. 245). Entendemos também, a relevância do desafio proposto ao estudante em refletir sobre a heterogeneidade da linguagem e, assim, trazer à tona a discussão sobre o preconceito linguístico e sobre a pertinência do conhecimento dos gêneros textuais, do

\footnotetext{
${ }^{3}$ Neste caso, dos gêneros aos quais os usuários são agentes na produção de conteúdo, mais especificamente voltado à Tecnologia da Comunicação do que da Informação.

${ }^{4}$ Inclusive os informais, tais como, os posts, e as conversas mediadas por computador (os chats).
} 


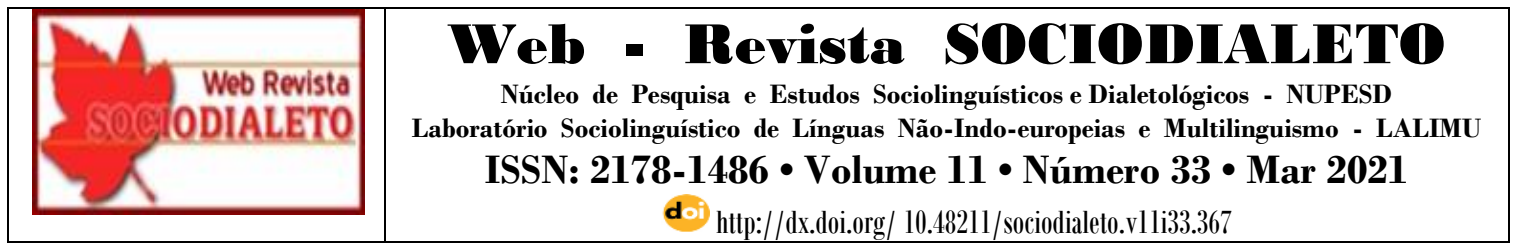

reconhecimento da escrita com características de fala e do contexto de situação, visando uma participação bem-sucedida na sociedade.

$\mathrm{Na}$ próxima seção, apresentamos um breve histórico sobre o surgimento e desenvolvimento da escrita virtual, linguagem conhecida como internetês, atentando-nos às condições particulares de fala e escrita nos eventos comunicativos diversos.

\section{Práticas de escrita na internet}

Que a escrita tem mais prestígio do que a fala, não há como argumentos contrários (STREET 1995 apud MARCUSCHI; DIONÍSIO, 2007) ${ }^{5}$. Mesmo sendo a fala mais antiga do que a escrita, o domínio desta colocou e coloca até hoje, os sujeitos que não dominam a escrita, em situação de desvantagem ${ }^{6}$. Já no estabelecimento do Estadonação ${ }^{7}$, a escrita teve papel estratégico junto ao projeto de engessamento de uma linguagem e cidadania homogêneas dentro de um espaço geográfico. O prestígio dado à língua padrão era estendido ao domínio da modalidade escrita que garantia o exercício pleno da cidadania em detrimento do domínio somente da língua falada (BUZATO, 2009).

O desenvolvimento da internet e o estabelecimento da Web 2.0 reconfiguraram a dicotomia que havia até então entre fala e da escrita ${ }^{8}$. Graças ao contexto digital e as condições de interação mediada, a escrita incorporou características de fala, tais como a abreviação das palavras, a eliminação de vogais, acentos, vírgulas e sinais de pontuação, originando, além de uma variação da escrita, um novo sistema gráfico: o internetês. Para dar conta das pistas contextuais, a possiblidade da inclusão de cores no pano de fundo dos textos (em blogs e posts, por exemplo); do uso de emoticons; de formatos de letras

\footnotetext{
${ }^{5}$ Street refere-se ao prestígio social da escrita, em sociedades contemporâneas.

${ }^{6}$ Por exemplo, as redações do vestibular e do ENEM e, no meio social, "não há como pegar um ônibus ou encontrar uma rua sem antes decifrar os nomes, as marcas ou dados codificados na escrita que os acompanha." (Marcuschi, 2007)

${ }^{7}$ Entre o final do século XVII e início do século XX.

${ }^{8}$ No sentido de popularizar e publicizar padrões de práticas de escrita com características de fala.
} 


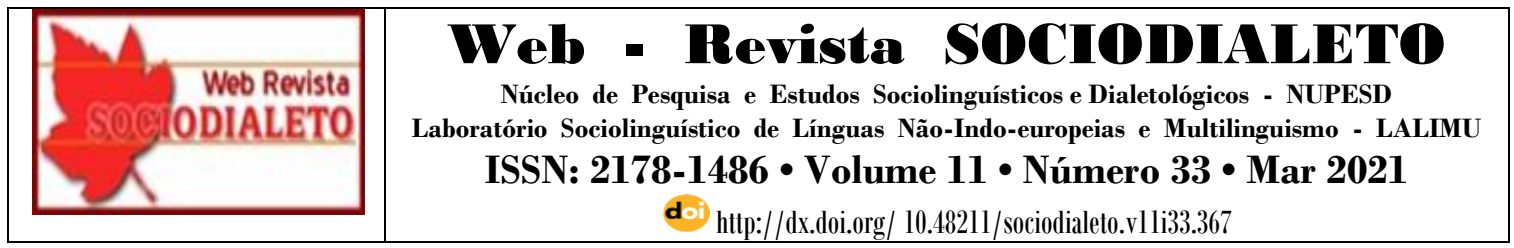

diversos; de desenhos e sons junto ao texto - conferiu um caráter mais lúdico à interação, indicando, por exemplo, estados de humor e sentimentos em relação ao interlocutor. Tais pistas ocupam-se do aspecto semântico na comunicação digital. São propiciamentos tecnológicos que conferem o caráter multimodal da comunicação virtual (PAIVA, 2016). São, também, exemplos das formas próprias de legitimar as práticas do meio digital, as quais Lévy (1999) refere-se quando sugere, já no final dos anos 90, que o movimento da cibercultura faria o mesmo processo que regularizou o enraizamento da cultura escrita nas sociedades modernas, na validação da forma de aquisição de conteúdo fora de contexto.

A escrita digital, fruto da cibercultura ${ }^{9}$ inaugura uma nova modalidade de comunicação, mais abrangente e mais democrática, pelo menos em contextos informais de interação, porque permite a participação de sujeitos que não tiveram acesso a modelos tradicionais de escrita ${ }^{10}$. A digitação, nesses contextos, exige uma nova lógica, diferente da convencionalizada pela cultura escrita. Komesu e Tenani (2009) definem o internetês como uma

forma grafolinguística que se difundiu em textos como chats, blogs e demais redes sociais. [...] A prática da abreviação, o banimento da acentuação gráfica, o acréscimo ou a repetição de vogais, as modificações do registro padrão, com troca ou com omissão de letras, são alguns dos traços que podem ser observados na ortografia desse texto $[\ldots](2009$, p. 624$)$.

O internetês abrange as características da fala por exigir mais dinamicidade nas trocas, improviso e, por essa razão, mais espontaneidade. Todavia, assim como a escrita formal, a escrita com características de fala também segue regras de convenções, comuns no momento da interação. Do contrário, a comunicação não acontece. Saber o modo apropriado de abreviar uma palavra, de escrever uma palavra cifrada, o significado da grafia das palavras em letra maiúscula, etc. são aspectos esperados pelos interlocutores e

\footnotetext{
${ }^{9}$ Segundo Lévy, a cibercultura é um “conjunto de técnicas (materiais e intelectuais), hábitos práticos, atitudes, modos de pensar e valores que se desenvolvem mutuamente no ciberespaço" (p. 17).

${ }^{10}$ Refiro-me a pessoas que passaram por um processo mínimo de alfabetização, por exemplo, as que cursaram somente o ensino fundamental I.
} 
é o que garantirá o sucesso ${ }^{11}$ da interação. Ou seja, mesmo sendo um contexto informal, não escolar, ainda assim é regido por regras que são compartilhadas pelos participantes.

Marcuschi e Dionísio (2007) esclarecem que fala e escrita "distinguem-se quanto ao meio utilizado" e "em certo sentido, esta é a única distinção dicotômica entre fala e escrita e com repercussões significativas, na medida em que se funda na forma de representação.” (p. 21). A marca da escrita é a grafia que tem como suporte o papel, por exemplo. A fala é marcada pelo som que é efêmero e não tem necessariamente um suporte. Tem, no entanto, traços que a escrita preenche com a pontuação, tais como, a entoação, as pausas, o sotaque, etc. Esses autores ressaltam que "a consequência mais importante é a que diz respeito à grafia dos sons, que, na fase inicial da alfabetização, oferece muitos problemas, pois símbolos diversos representam o mesmo som” (p. 21-22). Assim, o fato de o número de fonemas das línguas ser maior que o número das letras influencia a escrita na comunicação virtual pois, nos termos de Reis e Ruiz (2006), esta tenta acompanhar a velocidade do pensamento. Apresentamos exemplos dessa influência na análise dos dados.

\section{Contextos de produção de fala e escrita}

Conforme pontuamos previamente, embora se utilizem do mesmo sistema linguístico, fala e escrita são duas modalidades da língua, cada uma com características próprias (KOCH; ELIAS, 2012). A língua falada emerge no momento da interação, enquanto na escrita, os modos de recepção e produção não acontecem simultaneamente. $\mathrm{Na}$ comunicação síncrona do meio virtual, essas características são ressignificadas: o texto escrito adquire as características de fala, tais como marcas de espontaneidade e informalidade. Sendo as informações nesses contextos limitadas ao texto digitado, é de nosso interesse observar se os participantes desta pesquisa identificam essas marcas, especificamente os aspectos sintáticos das sentenças (ortografia, sintaxe, morfologia) e o

\footnotetext{
${ }^{11}$ Sucesso sob uma ótica subjetiva, ou ainda, se comparado à comunicação face a face.
} 


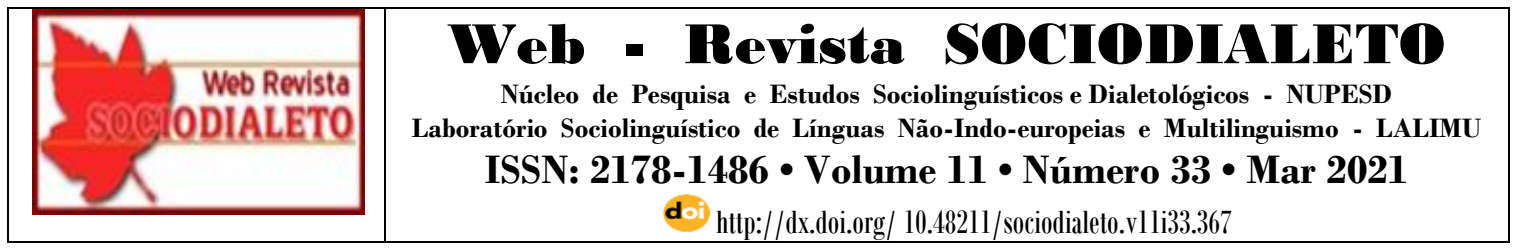

internetês, ambos produzidos no meio virtual, tendo como parâmetro a norma padrão que aprendem na escola. A relevância desse tipo de análise está na identificação que os participantes fazem dos contextos físico e virtual e no modo como transitam entre eles. Podemos dizer que as redes sociais virtuais são contextos de práticas cotidianas ${ }^{12}$ do público-alvo. Nelas, a representação textual das ações e das expressões faciais faz da linguagem o recurso principal de criação da realidade na Comunicação Mediada por Computador (CMC) (HERRING, 2001), a qual possui regras próprias que divergem da produção exigida na produção escrita na escola.

Chamamos a atenção para a importância da noção de contexto, para uma participação bem-sucedida, em situações on e offline. Trabalhada na escola, essa noção pode contribuir para a tomada de consciência dos estudantes quanto às práticas situadas de produção escrita. Ancoramo-nos nos pressupostos da Linguística Sistêmico-Funcional (LSF), para a discorrer sobre a necessidade do trabalho de identificação de gênero e contexto no meio escolar, incluindo os contextos virtuais que não seguem as normas da língua padrão. Para salientar a importância da descrição do contexto na investigação da linguagem, Eckert (apud MOTTA-ROTH, 2006, p. 155) afirma que "é central compreender os interactantes em uma situação comunicativa, a ideia que têm de si mesmos e do mundo e o que produzem com a linguagem". Halliday e Matthiessen (2004) argumentam que a conexão com o mundo e com as pessoas é feita através de escolhas linguísticas que correspondem à representação da experiência. Na conexão entre texto e contexto, o falante/escritor expressa sua experiência. A análise dos níveis gramatical e semântico da produção revela como essa prática é materializada na linguagem, sendo as experiências no mundo social, relacionadas na integração dos campos lexicogramatical e semântico.

Para este estudo, a contribuição da LSF está na divisão imaginária que guia o mapa mental (abstrato) dos usuários da língua, nas variáveis técnicas e situacionais disponíveis e utilizadas na publicação de posts no Facebook. Essa divisão segue regras dos contextos de situação e cultura (FAIRCLOUGH, 1992). O contexto de situação realiza o nível

\footnotetext{
${ }^{12} \mathrm{E}$ espontâneas, se comparados ao contexto e à produção escolar.
} 


\begin{tabular}{|c|c|}
\hline $\begin{array}{r}\text { Web Revista } \\
\text { ODIALETO }\end{array}$ & 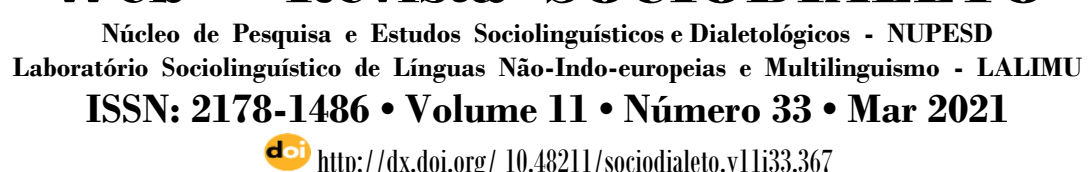 \\
\hline
\end{tabular}

semântico das escolhas, sendo a inserção de texto escrito ou falado guiada pelo gênero e registro mais adequados para a situação (MARTIN, 1992). O contexto de cultura é o lugar onde os sujeitos fazem sentido do que leem e escutam (LEMKE, 1995). Por limitações de espaço, neste estudo, concentramo-nos no contexto de situação. Este informa o registro do acontecimento, determina e corresponde ao tipo de linguagem utilizada em contextos específicos (HALLIDAY; MATTHIESSEN, 2004) e está dividido nas esferas campo, relação e modo, conforme indicado na tabela a seguir. Nela, apresentamos o contexto de situação dos dados coletados para a confecção deste estudo:

Quadro 1: elementos que compõem o contexto de situação (EGGINS; MARTIN, 1997).

\begin{tabular}{|c|c|c|}
\hline Campo & Relação & Modo \\
\hline $\begin{array}{l}\text { O que está } \\
\text { (conteúdo)/como acontecendo } \\
\text { acontecendo }\end{array}$ & $\begin{array}{l}\text { Papel assumido pelos } \\
\text { participantes/ tipo de relação } \\
\text { social que determina o status da } \\
\text { amizade }\end{array}$ & $\begin{array}{l}\text { Recursos utilizados na interação } \\
\text { relacionados à metafunção } \\
\text { interpessoal }\end{array}$ \\
\hline $\begin{array}{l}\text { Posts públicos na internet (modo } \\
\text { assíncrono), }\end{array}$ & $\begin{array}{l}\text { Amigos virtuais em uma rede } \\
\text { social/ Declarações e conselhos } \\
\text { não modalizados. }\end{array}$ & $\begin{array}{l}\text { Meio eletrônico: comunicação } \\
\text { escrita com status de língua } \\
\text { falada } \\
\text { gramaticais, } \\
\text { internetês. }\end{array}$ \\
\hline
\end{tabular}

Cientes de que as situações discursivas não acontecem em um vácuo social (MOTTA-ROTH, 2006) e do contexto de situação em que foram produzidas, a seguir, apresentamos a metodologia de pesquisa utilizada neste estudo, seguida da análise dos dados.

\section{Metodologia}

Trata-se de um estudo exploratório, com características de pesquisas quantitativa e qualitativa. Quantitativa porque analisamos o número de acertos e 'erros' das duas turmas, na identificação/não identificação do que foi proposto. É, também, qualitativa porque analisamos, caso a caso, as ações dos estudantes na identificação e reescrita. Sugerimos, a partir dos resultados, os possíveis efeitos da escrita virtual na escrita escolar, bem como um modo de promover a popularização de práticas linguísticas. 


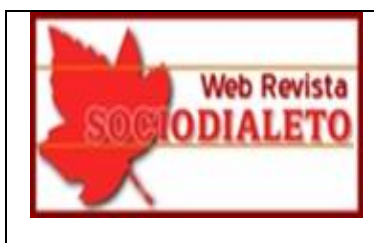

Web - Revista SOCIODIALETO

Núcleo de Pesquisa e Estudos Sociolinguísticos e Dialetológicos - NUPESD

Laboratório Sociolinguístico de Línguas Não-Indo-europeias e Multilinguismo - LALIMU

ISSN: 2178-1486 • Volume 11 • Número 33・Mar 2021

doi) http://dx.doi.org/ 10.48211/sociodialeto.vlli33.367

A fim de verificar a capacidade dos participantes da pesquisa para identificar e reescrever posts da internet que continham marcas de internetês, duas professoras de português de duas escolas, uma pública e uma privada, pediram que 19 estudantes da escola pública e 16 da escola privada, matriculados no $1^{\circ}$ ano do ensino médio, lessem quatro posts $^{13}$ e reescrevessem o que julgassem que não estava escrito de acordo com a norma padrão da língua portuguesa. Analisamos o trabalho de 10 estudantes de cada turma $^{14}$, os quais escolhemos aleatoriamente. A análise foi feita manualmente.

Em concordância com a definição da linguagem do internetês, proposta por Komesu e Tenani (2009) e os fatores relacionados à grafia dos sons salientados por Marcuschi e Dionísio (2007), definimos para a análise as categorias descritas no Quadro 1, a seguir:

Quadro 1: palavras e abreviações para análise de identificação de inadequação e reescrita.

\begin{tabular}{|c|c|c|c|c|}
\hline $\begin{array}{l}\text { Banimento de } \\
\text { acentuação }\end{array}$ & $\begin{array}{l}\text { Modificação de } \\
\text { registro padrão }\end{array}$ & $\begin{array}{l}\text { Omissão de } \\
\text { letras }\end{array}$ & $\begin{array}{l}\text { Acréscimo/repetição } \\
\text { de letras }\end{array}$ & $\begin{array}{c}\text { Letras que } \\
\text { representam o } \\
\text { mesmo som }\end{array}$ \\
\hline $\begin{array}{l}\text { (1) ‘unico’ por } \\
\text { 'único' (I) }\end{array}$ & $\begin{array}{l}\text { (3) 'igual eu' por } \\
\text { 'igual a mim' } \\
\text { (IV) }\end{array}$ & $\begin{array}{l}\text { (6) 'Msm' por } \\
\text { 'mesmo' (III) }\end{array}$ & $\begin{array}{l}\text { (9) 'Foor' por 'for' } \\
\text { (IV) }\end{array}$ & $\begin{array}{l}\text { (12) 'nacer' por } \\
\text { 'nascer' (I) }\end{array}$ \\
\hline \multirow{2}{*}{$\begin{array}{l}\text { (2) 'ninguem' } \\
\text { por 'ninguém' } \\
\text { (IV) }\end{array}$} & $\begin{array}{l}\text { (4) 'nós fica' por } \\
\text { 'nós ficamos' (II) }\end{array}$ & $\begin{array}{l}\text { (7) 'Slah' por } \\
\text { 'Sei lá' (IV) }\end{array}$ & $\begin{array}{l}\text { (10) 'Nauum' por } \\
\text { 'não'(IV) }\end{array}$ & $\begin{array}{l}\text { (13) ceduzir' por } \\
\text { 'seduzir' (I) }\end{array}$ \\
\hline & $\begin{array}{l}\text { (5) 'pensa' por } \\
\text { 'pensar' (III) }\end{array}$ & $\begin{array}{l}\text { (8) 'NH' por } \\
\text { 'né' (IV) }\end{array}$ & $\begin{array}{l}\text { (11) 'Sejaah' por } \\
\text { 'seja' (IV) }\end{array}$ & $\begin{array}{l}\text { (14) 'serto' por } \\
\text { 'certo'(I) }\end{array}$ \\
\hline
\end{tabular}

O Quadro 2 traz os resultados da análise feita pelos estudantes, de catorze posts. Dentre as inadequações que identificamos, escolhemos catorze, devido a questões de espaço. Procuramos escolher inadequações que contemplassem diferentes aspectos do internetês e da gramática padrão, passíveis de confusão.

\footnotetext{
${ }^{13}$ A proposta inicial era a análise de 7 posts, mas ao verificar o conteúdo das mensagens, a coordenação de uma das escolas autorizou a distribuição de somente 4 dos 7 posts propostos, os quais encontram-se nos anexos deste artigo.

${ }^{14}$ Julgamos que a análise da metade dos trabalhos feitos já seria suficiente para buscarmos os objetivos propostos.

${ }^{15}$ Os números em parênteses correspondem ao número dos posts, localizados nos anexos deste estudo.
} 


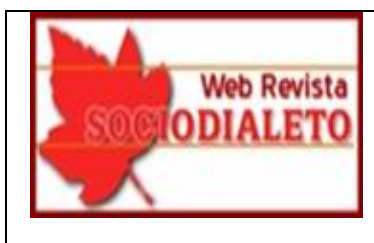

Web - Revista SOCIODIALETO

Núcleo de Pesquisa e Estudos Sociolinguísticos e Dialetológicos - NUPESD

Laboratório Sociolinguístico de Línguas Não-Indo-europeias e Multilinguismo - LALIMU

ISSN: 2178-1486 • Volume 11 • Número 33 • Mar 2021

doi http://dx.doi.org/ 10.4821l/sociodialeto.vlli33.367

Quadro 2: Desempenho dos estudantes das escolas pública e privada na identificação de inadequações gramaticais

\begin{tabular}{|c|c|c|c|c|c|c|c|c|c|c|c|c|c|c|}
\hline & (1) & (2) & (3) & (4) & (5) & (6) & (7) & (8) & (9) & (10) & (11) & $(12)$ & (13) & (14) \\
\hline $\begin{array}{lr}\text { Identificou } & \text { e } \\
\text { reescreveu } & - \\
\text { escola pública }\end{array}$ & 4 & 6 & 2 & 6 & 4 & 9 & 7 & 2 & 9 & 10 & 10 & 9 & 8 & 4 \\
\hline $\begin{array}{ll}\text { Identificou } & \text { e } \\
\text { reescreveu } & - \\
\text { escola privada } & \end{array}$ & 9 & 8 & 5 & 8 & 5 & 5 & 5 & 4 & 9 & 9 & 9 & 9 & 9 & 7 \\
\hline $\begin{array}{l}\text { Não identificou } \\
\text { (mesma } \\
\text { reescrita)- } \\
\text { escola pública }\end{array}$ & 6 & 4 & 8 & 4 & 6 & 2 & 0 & - & 1 & - & - & 1 & - & - \\
\hline $\begin{array}{l}\text { Não identificou } \\
\text { (mesma } \\
\text { reescrita) } \\
\text { escola privada }\end{array}$ & 1 & 2 & 5 & 2 & 5 & 0 & - & - & - & - & - & - & - & - \\
\hline $\begin{array}{lr}\text { Identificou } & \text { e } \\
\text { reescreveu } & \text { de } \\
\text { modo não } & \text { norrespondente) } \\
\text {-escola pública }\end{array}$ & - & - & - & - & - & $1 *$ & $1 * *$ & $1 * * *$ & - & - & - & - & - & - \\
\hline $\begin{array}{l}\text { Não reescreveu } \\
\text {-escola privada }\end{array}$ & - & - & - & - & - & 5 & 5 & 6 & - & 1 & 1 & - & 1 & 3 \\
\hline $\begin{array}{l}\text { Não reescreveu } \\
\text {-escola pública }\end{array}$ & - & - & - & - & - & - & 2 & 7 & 1 & - & - & - & 2 & 6 \\
\hline $\begin{array}{l}\text { Identificou } \\
\text { (escrita fora do } \\
\text { padrão) - escola } \\
\text { privada }\end{array}$ & - & - & - & - & - & - & - & - & 1 & - & - & $1 * * * *$ & - & - \\
\hline
\end{tabular}

Os números em parênteses correspondem ao item analisado, conforme o Quadro 1. Os números fora dos parênteses representam, de 1 a 10, os acertos e erros cometidos, de acordo com o que foi solicitado. No geral, avaliamos insatisfatórios os resultados, devido ao grau de escolaridade das turmas e por tratar-se de uma atividade monitorada. A escola privada apresentou breve vantagem em relação à escola pública, na identificação e reescrita adequada das palavras selecionadas: $72,1 \%$ e $64,2 \%$ respectivamente. Consideramos esse resultado relacionado às experiências além das práticas escolares, em outros contextos e, também, ao perfil sociolinguístico dos falantes.

O número de vezes que os estudantes da escola pública não reconheceu as inadequações e as reescreveu sem alterações foi mais que o dobro (32 vezes) do que o registrado nos resultados da escola privada (15 vezes), fator que vai ao encontro da 


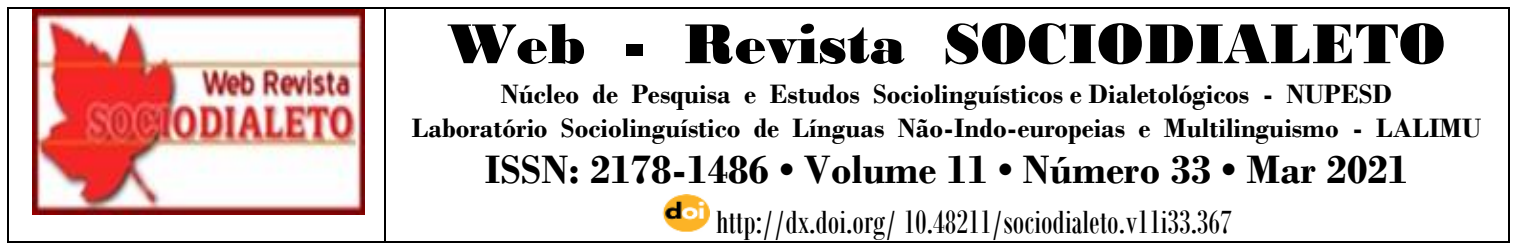

sugestão da proposta de exercícios de comparação entre a língua escrita formal e a língua escrita da internet.

Dos catorze exercícios propostos, a inadequação 'igual eu' foi a menos identificada e reescrita na norma padrão 'igual a mim' pelos participantes da escola pública. Neste caso, é interessante perceber que na fala, é comum o uso da preposição 'a' em 'igual a você', 'igual a Fulano', mas o mesmo não é tão comum quando se trata do próprio falante: 'igual eu' ${ }^{16}$. No entanto, assim como nos outros exemplos, o adjetivo 'igual' é regido pela preposição 'a' que exige um complemento nominal correspondente. Somente $20 \%$ dos estudantes da escola pública reescreveu adequadamente essa expressão. Na escola privada, foram $50 \%$ de acertos.

A concordância verbal exigida no exercício (4) 'nós ficamos' ao invés do 'nós fica' foi verificada com sucesso por $60 \%$ dos estudantes da escola pública e $80 \%$ da escola privada. Em um dos acertos da escola privada, consideramos a reescrita 'a gente fica', pois, embora 'a gente' não faça parte da norma padrão, concentramo-nos, neste exercício especificamente, no quesito concordância. Mollica (2003) salienta o alto índice de confusão de concordância verbal quando, na sentença, o sujeito não está ao lado do verbo. Todavia, alerta que mesmo em situações nas quais estão lado a lado, como é o caso do exercício 4 proposto nesta atividade, a concordância é muitas vezes estabelecida com o adjunto e não com o sujeito. Em 'nós fica de patrão', a inadequação parece ter seguido a lógica 'fico patrão', o que comprovaria a premissa de Mollica.

Quanto às palavras que exigem o acento agudo, somente $40 \%$ dos estudantes da escola pública acentuou a palavra 'único' na reescrita. O acento na palavra 'ninguém' foi percebido e reescrito por $60 \%$. Em comparação, o resultado da escola privada foi de $80 \%$ na reescrita de 'único' e 90\% na reescrita de 'ninguém'. Cunha e Cintra (2001) classificam o acento agudo como um sinal auxiliar, para a indicar a pronúncia exata das palavras. Além deste, outros sinais acessórios da escrita são os acentos grave (c), agudo (') e circunflexo $\left(^{\wedge}\right)$; o til $(\sim)$ utilizado sobre 'o' 'a' e 'o' para indicar a nasalidade dessas vogais. Como não são visualizados na fala, o uso de tais símbolos não é uma regra no

\footnotetext{
${ }^{16}$ Agradecemos ao nosso colega, prof. Isaias Munis Batista, por esta reflexão, na análise dos dados.
} 


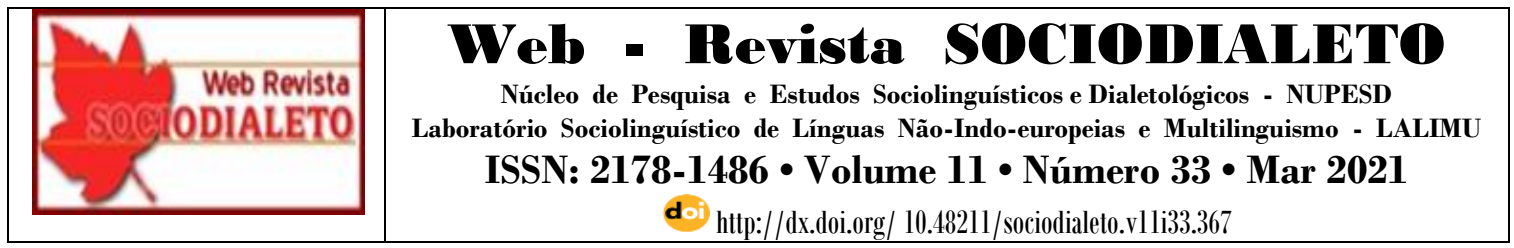

internetês. Todavia, observamos que este foi usado no pronome 'nós', no exercício (4), 'nós fica' e reproduzido pelos estudantes, talvez pela necessidade da distinção sonora entre 'nós' e 'nos', pronome oblíquo da $1^{\mathrm{a}}$ pessoa do plural. Apesar de improvável a confusão, devido a sua posição na sentença, o imediatismo característico da escrita virtual parece ter influenciado o produtor do post, no sentido de evitar equívocos no momento da leitura, mesmo que para isso tenha levado mais tempo do que o normal, na escrita com o acento.

Para as letras que representam o mesmo som, o resultado da escola publica chamou a atenção: somente $40 \%$ reescreveu 'certo' com 'c' ao invés de 'serto', como apresentado. $\mathrm{Na}$ escola privada, a porcentagem de acertos foi de $70 \%$, resultado que também surpreendeu uma vez que ponderamos que esta palavra seja comum no ambiente escolar e não apresente indícios para confusão de troca de letras, mesmo tendo o mesmo som.

No que concerne aos marcadores orais, os dois grupos tomaram uma atitude semelhante: quase que em sua totalidade, não identificaram nem reescreveram adequadamente os marcadores orais 'sei lá' e 'né'. Interpretamos esse fato como uma tomada de consciência sobre expressões características da fala, as quais seriam improváveis em um texto offline, restrito, então, apenas à escrita virtual. Essa interpretação responde, em certa medida, ao terceiro ponto de nossa investigaçào: a consciência dos dois grupos sobre gêneros textuais e questões de situacionalidade.

O cancelamento da vibrante /R/ em posição final na palavra 'pensar', foi reescrito adequadamente por $50 \%$ dos estudantes privada e $40 \%$ da escola pública. Ou seja, mesmo monitorados, metade de um grupo e mais da metade do outro não registrou a inadequação da palavra, na reescrita. Mollica (2003) explica que o problema ortográfico das finais vibrantes concentra-se nos casos de posição final, em sílabas tônicas e formas verbais infinitivas, tais como o caso apresentado nesta análise Os resultados de seu estudo indicam que o cancelamento da vibrante em posição final e a dificuldade na reescrita é um fenômeno que merece atenção mesmo em estágios mais avançados de escolarização, por indicar uma mudança em curso na língua. 


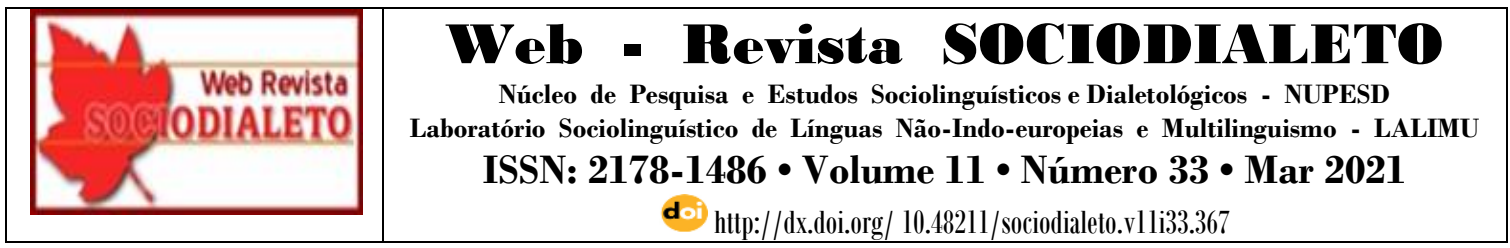

O reconhecimento e reescrita de palavras com acréscimo e a repetição de letras na meio online não foi um problema de para os estudantes dos dois grupos.

Com base nesses resultados, podemos dizer que a escrita digital influenciou/a o conhecimento dos grupos escolhidos sobre a escrita da norma padrão, pois, considerando que os participantes cursavam o $1^{\circ}$ ano do ensino médio, sugerimos uma atividade com palavras e construções gramaticais simples, para identificação e reescrita. O resultado geral foi abaixo de 75\%, indicando, assim, um conhecimento médio da norma padrão.

Entretanto, dois aspectos chamaram nossa atenção: primeiro a manutenção do acento agudo na $1^{\text {a }}$ pessoa do singular 'nós', no exercício 4, tanto do produtor do post quanto da maioria que o analisou e, segundo, a não reescrita de expressões usadas estritamente na fala informal: os exercícios 7 e 8 ('sei lá' e 'né?'). Se inferirmos que estes foram reconhecidos, mas não foram reescritos por não fazerem parte da norma padrão, podemos dizer que os dois grupos tiveram consciência da linguagem dos gêneros textuais e das situações de uso da linguagem. As inadequações estariam, então, relacionadas ao que desconhecem linguisticamente por falta do uso ou à falta de relevância ou atenção, como foi o caso da não reescrita da palavra 'serto'.

Os estudantes da escola privada tiveram um desempenho melhor do que os estudantes da escola pública, uma diferença de 7,9\%. Esse resultado não coincidiu com nossa hipótese inicial e nos fez ponderar sobre fatores que vão além da experiência escolar, mas relacionados à monitoração estilística nos contextos da comunidades de prática que os estudantes participam. O mesmo acontece com o material impresso a que têm acesso, conforme observa Gee (2000) quando afirma que o uso da escrita em materiais impressos varia muito entre as classes sociais mais favorecidas e as menos favorecidas (MONTE MÓR; MENEZES DE SOUZA, 2006).

Os resultados desta breve análise nos incentivou a propor atividades em sala de aula que abarquem diferentes práticas linguísticas. 


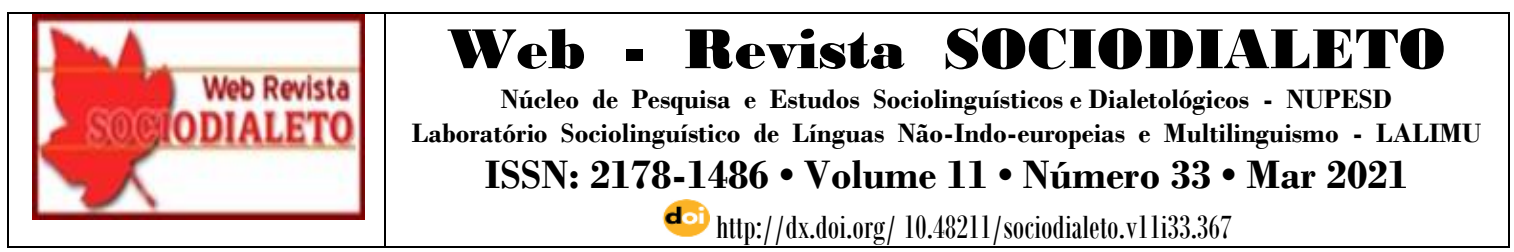

\section{Considerações Finais}

Neste artigo, apresentamos uma breve análise da performance de estudantes de uma escola privada e de uma escola pública, na identificação e reescrita de inadequações gramaticais e do internetês. Apesar do corpus reduzido, os resultados nos deram subsídios para ampliar a pesquisa e sugerir um trabalho de intervenção nas escolas, por meio da inclusão do estudo do contexto de situação no planejamento de curso do ensino médio.

Entendemos que o trabalho comparativo da linguagem em diferentes contextos, com base nos pressupostos da LSF, pode potencializar a compreensão das características que distinguem a escrita formal da escrita na internet, da situação efêmera da interação escrita que não foi prevista no surgimento da escrita formal. Longe de ser desprestigiada, a língua do internetês é, segundo nosso entendimento, uma forma de comunicação legítima em determinados contextos virtuais. Ao invés de condená-la, a escola pode abarcá-la, propondo o trabalho com a identificação do contexto, dos interlocutores envolvidos e do meio utilizado para a interação, visando, assim, o aprimoramento da escrita formal.

\section{Referências}

BUZATO, Marcelo El Khouri. Letramento e inclusão: do estado-nação à era das TIC. Revista D.E.L.T.A., v. 25, $\mathrm{n}^{\mathrm{o}}$ 1, p. 01-38, 2009. Disponível em: <http://dx.doi.org/10.1590/S0102- 44502009000100001>. Acesso em: 14 mai. 2019.

CUNHA, Celso; CINTRA, Lindney. Nova gramática do português contemporâneo. $3^{\mathrm{a}}$. ed. Rio de Janeiro: Nova Fronteira, 2001. 800 p.

EGGINS, Suzanne.; MARTIN, James. R. Genres and registers of discourse. In: VAN DIJK, T. A. (Ed.) Discourse as structure and process. Discourse Studies: A Multidisciplinary Introduction, v. 1. London: Sage, 1997. p. 230-256.

FREITAG, Raquel Meister Ko; FONSECA E SILVA, Marineide. Uma análise sociolinguística da língua utilizada na internet: implicações para o ensino de língua 


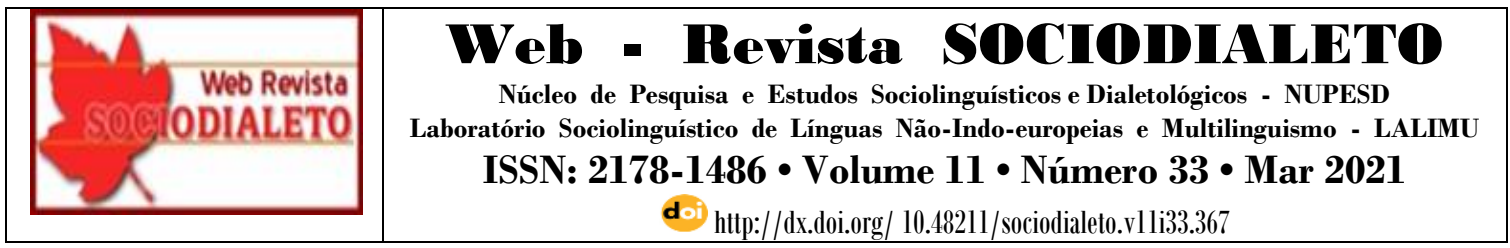

portuguesa. Revista Intercâmbio, v. XV. São Paulo: LAEL/PUC, 2006. Disponível em https://revistas.pucsp.br/index.php/intercambio/article/viewFile/3689/2414. Acesso em 03 abril 2019.

GEE, James Paul. New people in new worlds: networks, the new capitalism and schools. In: COPE, B.; KALANTZIS, M. Multiliteracies: literacy learning and the design of social futures. London: Routledge, 2000.

HALLIDAY, Michael A. K.; MATTHIESSEN, Christian An introduction to functional grammar. $3^{\text {rd }}$ ed. London: Hodder Arnold, 2004. 480 p.

HERRING. Susan C. Computer-mediated discourse. In: SCHIFFRIN, D.; TANNEN, D.; HAMILTON, H. (Eds.). The handbook of discourse analysis. Oxford: Blackwell Publishers, 2001. p. 612-634.

KOCH, Ingedore Villaça; ELIAS, Vanda Maria. Ler e Escrever: estratégias de produção textual. São Paulo: Contexto, 2012. 220 p.

KOMESU, Fabiana; TENANI, Luciani. Considerações sobre o conceito de "internetês"nos estudos da linguagem. Linguagem em (Dis)curso. Palhoça, SC, v. 9, n. 3, p. 621-643, set./dez. 2009. Disponível em http://www.scielo.br/pdf/ld/v9n3/10.pdf. Acesso em 03 de abril 2019.

LAVE, Jean; WEGNER, Etienne. Situated learning: legitimate peripheral participation. Cambridge: Cambridge University Press, 1991. 144 p.

LÉVY, Pierre. Cibercultura. Tradução de Carlos Irineu da Costa. São Paulo: Editora 34, 1999. $272 \mathrm{p}$.

MARCUSCHI, Luiz Antônio; DIONÍSIO, Angela Paiva (Orgs.). Fala e escrita. Belo Horizonte: Autêntica, 2007.

MARCUSCHI, Luiz Antônio. Oralidade e letramento como práticas sociais. In: MARCUSCHI, L. A.; DIONÍSIO, A. P. (Orgs.). Fala e escrita. Belo Horizonte: Autêntica, 2007. p. 31-55.

MOLLICA, Maria Cecília; BATISTA, Hadinei Ribeiro. Efeitos da Web nos estilos monitorados. In: MOLLICA, M.C.M.; SILVA, C. A. P. P. G.; BATISTA, H. R. Sujeitos em ambientes virtuais: Festschriften para Stella Maris Bortoni-Ricardo. São Paulo: Parábola, 2015. p. 67-86.

MOLLICA, Maria Cecília. Da linguagem coloquial à escrita padrão. Rio de Janeiro: 7Letras, 2003. 146 p.

MOTTA-ROTH, Desirée. Questões de metodologia em análise de gêneros. In: KARWOSKI, A.M.; GAYDECZKA, B.; BRITO, S. K. Gêneros textuais: reflexões e ensino. $2^{\mathrm{a}}$ ed. Rio de Janeiro: Ed. Lucerna, 2006. p. 145-163.

MORIN, José Manuel. Os novos espaços de atuação do professor com as tecnologias. In: ROMANOWSKI, Joana Paulin et al (Orgs). Conhecimento local e conhecimento universal: Diversidade, mídias e tecnologias na educação. V. 2, Curitiba, Champagnat, 2004

p. 245-253.

Disponível

em 


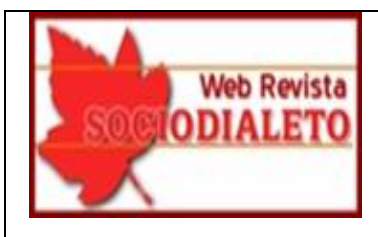

Web - Revista SACIOIDIALETO

Núcleo de Pesquisa e Estudos Sociolinguísticos e Dialetológicos - NUPESD

Laboratório Sociolinguístico de Línguas Não-Indo-europeias e Multilinguismo - LALIMU

ISSN: 2178-1486 • Volume 11 • Número 33・Mar 2021

doi http://dx.doi.org/ 10.4821l/sociodialeto.vlli33.367

http://www.ufrgs.br/nucleoead/documentos/moranOsnovos.htm. Acesso em 01 abril 2019.

PAIVA, Vera Lúcia Oliveira e. A linguagem dos emojis. Trabalhos em Linguística Aplicada, vol.55, n.2, p.379-401, 2016. Disponível em http://www.scielo.br/scielo.php?script=sci_abstract\&pid=S0103-

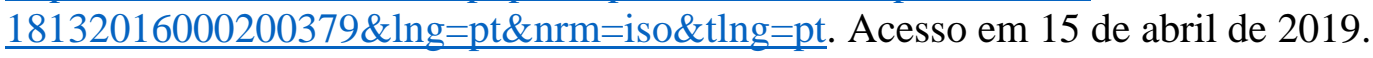


Núcleo de Pesquisa e Estudos Sociolinguísticos e Dialetológicos - NUPESD

Laboratório Sociolinguístico de Línguas Não-Indo-europeias e Multilinguismo - LALIMU

ISSN: 2178-1486 • Volume 11 • Número 33・Mar 2021

doi http://dx.doi.org/ 10.48211/sociodialeto.vlli33.367

\section{ANEXO}

Identifique as inadequações gramaticais e a linguagem do internetes nos posts abaixo e os reescreva, quando necessário, de acordo com a norma padrão da língua portuguesa:

I)

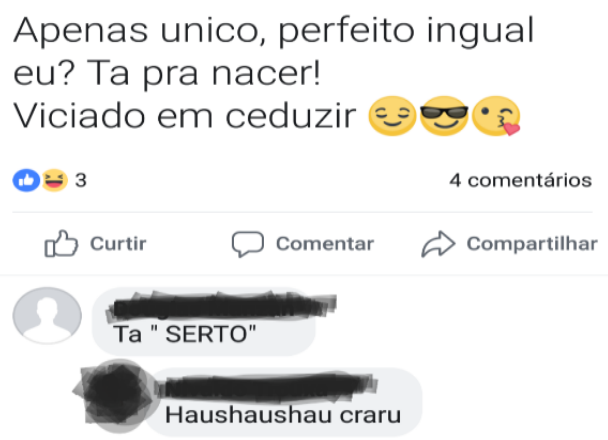

II)

Se der certo, nós fica de Patrão

厚

Nttv bpns 9

(1) 6

C Curtir $Q$ comentar $\Rightarrow$ Compartilhar

III)

17 de fev às 10:58

- Só Qué Ficar Tranquila Naum Pensa Em

Ninguem' $=0$ ss $=$ \#Feiaa_Msm $=0$

Slaah_Gosteii $\hat{\theta}-z z$

IV) 
Núcleo de Pesquisa e Estudos Sociolinguísticos e Dialetológicos - NUPESD Laboratório Sociolinguístico de Línguas Não-Indo-europeias e Multilinguismo - LALIMU ISSN: 2178-1486・Volume 11 • Número 33・Mar 2021 dol http://dx.doi.org/ 10.48211/sociodialeto.vlli33.367

— Q Pesquisar nas publicações, fotos...

Enquantooh Vocee Foor Ooh Queeh Oos Outroos Quereem Queeh Voocee Sejaah, Vocee Nauum Seráh Ninguém! $\square \cdot \bullet$ \#Sla_Gosteii .. O OGORDA QUE FALA NHE Q $-z^{\overline{2}}$

Recebido em: 30/11/2020 | Aprovado em: 25/01/2021. 